NBER WORKING PAPER SERIES

\title{
DEFINING PRICE STABILITY IN JAPAN: A VIEW FROM AMERICA
}

Christian Broda

David E. Weinstein

Working Paper 13255

http://www.nber.org/papers/w13255

\section{NATIONAL BUREAU OF ECONOMIC RESEARCH 1050 Massachusetts Avenue Cambridge, MA 02138 July 2007}

The authors wish to thank R. Anton Braun, Hugh Patrick, Masaaki Sato, and Shigenori Shiratsuka for comments. We wish to thank the Center for Japanese Economy and Business for research support and the National Science Foundation for support under grant SES-0452460. The views expressed herein are those of the author(s) and do not necessarily reflect the views of the National Bureau of Economic Research.

(C) 2007 by Christian Broda and David E. Weinstein. All rights reserved. Short sections of text, not to exceed two paragraphs, may be quoted without explicit permission provided that full credit, including (C) notice, is given to the source. 
Defining Price Stability in Japan: A View from America

Christian Broda and David E. Weinstein

NBER Working Paper No. 13255

July 2007

JEL No. E31,E5,H6

\begin{abstract}
$\underline{\text { ABSTRACT }}$
Japanese monetary and fiscal policy uses the consumer price index as a metric for price stability. Despite a major effort to improve the index, the Japanese methodology of calculating the CPI seems to have a large number of deficiencies. Little attention is paid in Japan to substitution biases and quality upgrading. This implies that important methodological differences have emerged between the U.S. and Japan since the U.S. started to correct for these biases in 1999. We estimate that using the new corrected U.S. methodology, Japan's deflation averaged 1.2 percent per year since 1999. This is more than twice the deflation suggested by Japanese national statistics. Ignoring these methodological differences misleading suggests that American real per capita consumption growth has been growing at a rate that is almost 2 percentage points higher than that of Japan between 1999 and 2006. When a common methodology is used Japan's growth has been much closer to that of the U.S. over this period. Moreover, we estimate that the bias of the Japanese CPI relative to a true cost-of-living index is around 2 percent per year. This overstatement in the Japanese CPI in combination with Japan's low inflation rate is likely to cost the government over 69 trillion yen -- or 14 percent of GDP -- over the next 10 years in increased social security expenses and debt service. For monetary policy, the overstatement of inflation suggests that if the BOJ adopts a formal inflation target without changing the current CPI methodology a lower band of less than 2 percent would not achieve its goal of price stability.

Christian Broda

University of Chicago

Graduate School of Business

5807 South Woodlawn Avenue

Chicago, IL 60637

and NBER

cbroda@chicagogsb.edu

David E. Weinstein

Columbia University

Department of Economics

420 W. 118th Street

MC 3308

New York, NY 10027

and NBER

dew35@columbia.edu
\end{abstract}




\section{Introduction}

On March 9, 2006, the Bank of Japan issued a statement clarifying its thinking on price stability: "Price stability is, conceptually, a state where the change in the price index without measurement bias is zero percent. Currently, there seems to be no significant bias in the Japanese consumer price index.” This confidence in the lack of bias in the Japanese CPI is particularly surprising since the Japanese national statistics office does not correct for even the most basic problems in standard index theory. By contrast, understanding biases in the US CPI has been a major undertaking that has produced many changes in the index in recent years. In this paper, we review how the differences between the Japanese and American way of calculating price indexes makes cross-country comparison based on national statistics highly misleading. We discuss the conceptual issues related to CPI measurement, the recent modifications to the US CPI and the implications that they have for fiscal and monetary policy in Japan. ${ }^{1}$

We begin by documenting that using the US methodology of calculating price indexes, Japan’s deflation averaged 1.2 percent per year since 1999. This is over two times more deflation than suggested by Japanese official statistics. This is a useful exercise because the US Bureau of Labor Statistics (BLS) has updated its procedures to correct for widely recognized problems in

\footnotetext{
${ }^{1}$ Measurement issues have plagued the Japanese CPI. For example, consider what happened in the first few months after the BOJ statement. After 5 straight months of positive year-on-year CPI inflation, the BOJ ended its policy of quantitative easing. After four more months of CPI growth of around 0.6 percent per year, the BOJ raised interest rates by 0.25 percent. However, little more than five months after the BOJ noted the that there was no bias in the Japanese CPI, the Ministry of Internal Affairs and Communications (MIAC) updated the CPI weights (which was just one of the eight possible sources of bias that the BOJ had dismissed) and revealed that inflation had been consistently negative (year on year) for every month until the BOJ raised rates. While inflation was standing at a positive 0.1 percent annual rate in March of 2006, it went negative in April (0.6 percent below the old CPI) following the end of quantitative easing. When the BOJ raised rates to 0.25 percent, inflation was only 0.2 percent. After the rate increases, deflationary pressures intensified. The latest numbers for March of this year reveal that year-on-year core inflation (the general index without fresh food) stood at -0.1 percent. Deflation has returned.
} 
standard price indexes and devotes substantially more resources to the calculation of prices indexes than Japan’s counterpart (MIAC). It also underscores the risks of ignoring methodological differences when comparing cross-country performances. If we ignore the methodological differences between the US and Japan and compare growth by looking at the official data of each country, we would conclude that American real per capita consumption has been growing at a rate that is around 2 percentage points higher than Japan's real per capita consumption during the 1999 - 2006 period. However, when we use a common methodology, Japan’s growth over this period has been much closer to that of America, being only 0.7 percentage points smaller.

The differences between CPI methodologies can be traced to simple improvements in the formulas used in the US that have not yet been implemented in Japan. As a result of the Boskin Commission in 1996, it became apparent that two basic corrections were required to improve the measurement of prices. First, the so-called "substitution bias" had to be corrected. Indexes used to compute prices should recognize the simple fact that when the price of, say, apples relative to oranges rise, the quantity demanded of apples is expected to fall. By ignoring the fall in apples purchased, conventional price indexes that use a fix weight for apples and oranges over time tend to overweight the importance of price increases. ${ }^{2}$ The US corrected for this problem with two successive modifications of the formulas used in computing the CPI in 1999 and 2002. Japan has not addressed the substitution bias. Second, the Commission concluded that hedonics should be used to capture the growth in quality in some fast-growing products like computers. By 2002, the BLS had extended the use of hedonic regression to estimate the value of items changing in quality to cellphones, computers, refrigerators among several other durable goods. Today hedonics are also used in the US for the pricing of Cable Television, Lodging away from Home,

\footnotetext{
${ }^{2}$ As expected this leads to an overstatement of the true cost-of-living index.
} 
and College Tuition and Fees. Japan only uses hedonics for computers since 2000 and for digital cameras since 2003. These two differences imply that even if all prices move identically in the US and Japan in 2007, the measured Japanese inflation will be around 0.8 percentage points higher than in the US.

The rest of the paper highlights the differences and implications between using simple atheoretic procedures of aggregating prices over a fixed basket of goods, like the Japanese CPI, and so-called cost-of-living (COLI) indexes, that measure the cost of maintaining a certain "standard of living," without restrictions on what is in the basket. Baring computational errors, atheoretic indexes are not wrong, they are just not informative. For this reason most economists recognize that the measurement goal of a CPI is a COLI. The stance of Japan's MIAC on this issue is confusing. On parts of its website it states that Japan's index is simply an atheoretic cost of goods index: "it is necessary to pay attention that the CPI intends to measure the price movements themselves, not to measure movements of living expenses with changes of varieties, qualities or quantities of goods and services.” This view suggests that the CPI may fluctuate even though these movements may not reflect changes in the cost of living. The absence of a theoretical justification underlying the CPI means that the Japanese CPI may not tell us how these price changes actually are affecting the cost of living. This, of course, raises concerns about what exactly the CPI is measuring.

However, on the same website in which the MIAC explains that the CPI is a not a measure of living expenses, it also argues that it is a cost of living index: "The index shows changes in the total amount of expenditure required to purchase the equivalent goods and services purchased by households in the base year”. The inconsistency of the two statements 
reflects the inherent tension between producing an atheoretic index and the desire to have that index mean something.

The absence of a theoretical underpinning for the CPI creates a conundrum for policy makers that is not unique to Japan. For example, if the MIAC produces indexes of prices that are determined only by the formula used, then there is little theoretical justification to define "price stability” following the existing CPI since the index is not measuring prices in a way that is easily interpretable in terms of economic fundamentals. We survey recent studies that show that new higher quality products are constantly replacing older products and that this process is mostly ignored by statistical offices. Since the overall quality available to consumers is rising, the cost-of-living index is falling at a faster pace than that implied by the formulas used by most agencies. Thus, there remains a substantial bias arising from new and higher quality goods in the CPI. This upward bias is estimated to be around 0.8 percent per year. This implies that together with other existing biases, the overall bias in the Japanese CPI relative to a true COLI is around 1.8 percent per year.

The implications of this bias are enormous. Many Japanese government transfers, such as public pensions, are indexed to the CPI. The conventional justification for this indexing is that in is required to maintain the "standard of living" of the elderly constant over time. However, if the CPI is biased upward, then this means that the government is spending vastly more than it should to keep the standard of living of the elderly constant over time. If this overstatement in the Japanese CPI is not corrected it will imply higher government expenses for over 69 trillion yen or 14 percent of GDP - over the next 10 years in increased social security transfers and debt service. For monetary policy, the overstatement of inflation suggests that if the BOJ adopts a 
formal inflation target without changing the current CPI methodology a lower band of less than 1.8 percent would not achieve a goal of price stability.

\section{Price Indexes in Japan and the US: Some Important Differences}

Much of the theoretical work for biases in the US CPI has been developed by government and academic economists interested in obtaining better measures of inflation. While the US has resisted officially using utility-theory based indexes, the BLS has implemented a large number of modifications to the CPI that make it perform more closely to this benchmark. Indeed much of the Boskin Commission's report was explicitly about eliminating deviations (biases) between the CPI and the Tornqvist index. ${ }^{3}$

The US has also benefited enormously from the government's interest in data collection. Ariga [2003] reports that in 2002, the US government spent 10 times more than Japan on the collection of statistics. Ariga documents that number actually understates the difference for a number of reasons. First, $68 \%$ of Japanese statisticians are involved in the collection of agricultural statistics (as opposed to 1.5\% in the US). Second, the Statistics Bureau of the MIAC (Ministry of Internal Affairs) has only 10 people with a masters level education and no one with a $\mathrm{PhD}$. The US government, by contrast employs 2000 statisticians and economists. While we could not find information on the training level of the statisticians at the BLS, every economist and statistician opening listed on the BLS website (checked on 8/25/06) required the applicant to have at least a masters degree. Moreover every economist and statistician in the BLS over Grade 9, which constitutes the vast majority of these positions, must hold a masters or higher degree. Taken together, the thirty-to-1 spending and manpower differences are likely to generate

\footnotetext{
${ }^{3}$ The Tornqvist index has the desirable property that it is superlative, that is it is a second order approximation to any arbitrary twice differentiable linear homogenous utility function. .
} 
substantial differences in the sophistication Japanese and US statistical agencies can bring to bear on data collection and processing.

It is therefore not surprising that the Japanese CPI is constructed using different procedures than those in the US. The Japanese CPI is constructed in accordance with the International Labor Organization minimum standards, but this is a low threshold. The typical member of the ILO has a per capita income one twentieth of Japan and cannot be expected to implement the sophisticated price measurements used in the US. As a result, the methodologies used by Japan and US differ substantially, and one should be very cautious doing cross-country comparisons of aggregate prices. To understand these differences, one needs to delve a bit deeper into the statistics.

The US CPI contains two levels of aggregation. At the upper level, 211 strata level price indexes in each of 38 areas (or regions) are combined either using a Laspeyres formula in the case of the standard CPI or a Tornqvist formula when using the chained CPI. ${ }^{4}$ This means that there are 8018 item-area indexes that are aggregated at the upper level. Each of these indexes is in turn based on a lower level sample of approximately ten price quotations per item-area (85,000 price quotes overall). This lower level price quotation is critical for the BLS's approach to price measurement. Almost all of the deviations from the standard Laspeyres index in the US case - hedonics, geometric averaging of prices, sample rotations, etc. - occurs at this lower level. Thus, while the upper level of the US CPI is Laspeyres, the lower level is a complex combination of geometric averages, hedonics, and imputations. Since much of the substitution by consumers is done at the lower level (among, say, different brands of the same good), than across

\footnotetext{
${ }^{4}$ Some of these strata are comprised of 2 or more Entry level items to account for different items within a strata. The 305 ELIs are aggregated into to the 211 strata in the CPI.
} 
different expenditure classes (e.g. cars vs. televisions), this two tiered approach corrects much of the substitution bias.

The Japanese CPI, by contrast, is much closer to a pure Laspeyres index. At the upper level, the Japanese CPI is more disaggregated than the US CPI. Japan uses 598 items in its CPI instead of the 211 strata used in the US, and surveys these prices in 167 municipalities across Japan as opposed to the 38 in the US. Thus, at the upper level, Japan has more than ten times the number of price series in its CPI calculation. However, there is a big cost to the significantly larger and more geographically dispersed sample: the lower level of the Japanese CPI is much smaller. To the extent that multiple prices are aggregated to form an upper level index, it is done using a simple average of the prices. Moreover most of the research on the Japanese CPI, with the notable exception of Ariga [2003]) has focused on issues at the upper level biases, leaving most of what the US has focused on untouched. For example, the Japanese do not use geometric averages or random samples of prices and only started to do hedonic regressions on personal computers and digital cameras recently.

How much do the Japanese gain from the greater geographic dispersion in the index? The answer is probably not much. Broda and Weinstein (2007b) use ACNielsen Homescan data to examine the prices of goods purchased in ten cities in the US. The major advantage of these data is that goods are defined using barcodes and hence the exact same goods can be compared in different cities. The results suggest that, at least for goods, there is very little dispersion in average prices across cities: the standard deviation in average prices of identical goods across cities is only 2 percent. Indeed there is more dispersion in prices within cities than across cities. Much of the difference in apparent price differentials across cities arises from different samples 
of goods. This suggests that the law of one price is a reasonable approximation for goods prices in the US. It is likely that given Japan's smaller land mass, prices are even more integrated.

This has an important policy implication for thinking about how data is collected in Japan and the US. If there is not much difference in the price of, say, a 0.5 liter bottle of Diet Coke in two cities, statistical agencies can save significant amounts of money by not collecting regional price information on goods (while maybe continuing to collect it for non-tradables like housing). This information could be used in Japan to increase the sample size of the lower level of the CPI.

\section{II.a. Lower Level Substitution Bias}

The Japanese CPI measures the current cost of a fixed basket of goods and services. As a fixed-quantity weight index ${ }^{5}$, the Laspeyres index tends to overstate increases in the cost of living because it ignores the substitutions that consumers make in response to changes in relative prices. For instance, if the price of Kirin bottles rises relative to the price of Asahi bottles, consumers will partially substitute the purchase of Kirin for that of Asahi. Since a fixed quantity weight index assigns a relatively higher share to Kirin (the product whose price has risen) than consumers do, the CPI will overestimate the increase in consumers cost of living.

A simple example can illustrate the extent of the bias. Assume that the typical Japanese consumer buys one bottle of Kirin and one bottle of Asahi a month at a cost of 300 yen per bottle. If the price of Kirin beer today rises to 600 yen and the price of Asahi falls to 150. Most consumers would switch their purchases towards Asahi, but a fixed quantity index like the Japanese CPI would record this set of price changes as inflation. If the Japanese CPI recorded the price of beer as 1 in the first year, the price index in the second year would be a 25 percent increase in the price of

\footnotetext{
${ }^{5}$ As the name suggests, a fixed-weight index adds prices of different goods and services using a quantity weight that is fixed over a long period of time, typically over 5 years.
} 
beer (i.e., $0.25=((600+150) /(300+300)-1)$. That is, the Japanese CPI methodology assumes that consumers continue to buy the same amount of Kirin and Asahi even after their prices change.

The high degree of geographic dispersion in the Japanese CPI, results in a very small sample at the lower level. For example, MIAC typically only uses one price quotation per itemarea as opposed to 10 in the US (Ariga [2003]), and only several dozen price quotations in the Tokyo metropolitan area. One of the major drawbacks of this procedure is that the Japanese CPI cannot make any adjustments for what the BLS calls “lower-level substitution”: the ability of consumers to switch away from high priced bands to low priced brands of a particular item in a particular region. ${ }^{6}$

The US corrects for this problem by randomly sampling prices and using geometric averaging at the lower level since 1999. The advantage of geometric averaging is that it allows for substitutability among the various goods that make up an item index. Since the US uses approximately 10 price quotations per item-area, the BLS has more flexibility in terms of how prices are aggregated into the index. In the example discussed above, the BLS would take the geometric average of the prices and produce an estimate of no inflation in the second year $(0=$ $\left.(2 * 0.5)^{\wedge} 0.5-1\right)$.

The US formulation is equivalent to assuming that goods have an elasticity of substitution of unity. Shapiro and Wilcox [1997] document that the geometric mean of prices is a close approximation of the superlative Tornqvist aggregator. This is not that surprising since the

\footnotetext{
${ }^{6}$ Sato (2007) argues that this avoids a bias in the CPI because simple averages of prices and geometric averages of prices will yield similar results if the goods sampled are chosen to be homogeneous and therefore do not exhibit large relative price fluctuations. While this point is correct, it reflects the fact that without random sampling, one cannot estimate the lower-level bias in the Japanese case. If the MIAC performed random sampling, the bias would be larger. Thus the measured low bias in the Japanese case is just an artifact of the non-random sample used in the analysis.
} 
geometric average is a first order log approximation of an arbitrary utility function while the Tornqvist can be thought of as a second order approximation.

But how important is this bias in reality? In the US, the quantitative importance of this adjustment has been estimated to quite large. Lebow, Roberts, and Stockton [1994] estimate that prior to the implementation of geometric averaging, the lower level substitution bias ranged from 0.3 -0.4 percentage points per year. Moulton and Smedley [1995] estimated that the switch to geometric weighting at the lower level biases the CPI upward by 0.5 percent per year. ${ }^{7}$ Shapiro and Wilcox [1997] put the bias in the range of 0 - 0.5 percent. Broda and Weinstein (2007) used ACNielsen Homescan data to compare a pure Laspeyres index with a Tornqvist index and found that lower level substitution created an upward bias of 0.4 percent per year. The similarity of these numbers despite coming from different data sets and arising from different methodologies suggests that it is reasonable to conjecture a large upward bias in Japan. Based on these estimates, we believe that a reasonable estimate of the upward bias due to lower level substitution to be around 0.4 percent per year in Japan as well.

One critique of this approach is offered by Shiratsuka (1999). Shiratsuka uses the methodology of the Boskin Commission report to estimate the bias, an approach that we mimic in this paper, and argues that the lower level substitution bias is only 0.1 percent per year. He summarizes his reasoning as follows:

"Since the Management and Coordination Agency does not release the price index of those lower than the item level, problems in aggregating individual sample prices into item levels have not been estimated. However, taking into account the fact that (1) the increase in the Japanese CPI is now at a low rate, thus biases caused by the index formula are deemed to be almost negligible; and (2) the classification of Japanese CPI items is more detailed than the item strata used in the United States, it can be safely assumed that biases caused in the process of aggregation of individual prices into item level are considerably smaller than the U.S. estimate of

\footnotetext{
${ }^{7}$ Greenlees argues the lower level bias in the US CPI prior to the introduction of geometric averages are 0.2 percentage points per year but, as the Boskin Commission documents, this lower number reflects the remaining bias after the BLS implemented procedures to reduce the lower-level substitution bias.
} 
0.25 percent. In this paper, I will assume the bias stemming from the process of aggregating individual prices to item level to be 0.10 percent, a figure derived as the difference between upper level substitution and lower level substitution, which were both estimated in the Boskin Report.” p. 82

The argument that low inflation leads to low relative price volatility seems problematic because there is no clear connection between relative price movements and aggregate price movements at these low levels of inflation. Prices could be rising in unison with no relative price changes, or alternatively there can be large relative movements in prices with no overall trend in prices. In the US, these deviations are enormous. Klenow and Kryvtsov (2005) find that in BLS data, the average monthly movement in a price quotation is 13.1 percent in a period of low US inflation. Similarly Broda and Weinstein (2007) find that in scanner data the typical quarterly movement in the average price of a good with a barcode is 8 percent for a similar period. This suggests that that there is vastly more price volatility at the individual good level than we observe at the aggregate level. Since the bias is driven by the high levels of price volatility of price quotations, the fact that aggregate inflation is low probably does not have much of an impact on the magnitude of the bias in low inflation environments.

Second, although Shiratsuka (1999) argues that the fact that Japanese item-strata are more numerous than those in the US compensates for the lower-level bias, this seems unlikely. The key point to bear in mind is that the lower-level substitution bias is a formula bias arising from the fact that the Laspeyres index does not allow for substitution at the lower level. This formula bias will be present regardless of the level of aggregation. Put simply, a Laspeyres index would exhibit formula bias even if one observed every price in the Japanese economy. 
Elsewhere Shiratsuka has argued that the lower-level substitution is a US specific problem that arises out of the US decision to do random sampling of prices. ${ }^{8}$ MIAC, by contrast, does not do random sampling of goods, but rather instructs its agents to select the best selling brands in the largest selling stores. Since MIAC typically instructs agents to select very similar goods at the lower level (for example, the beer index is composed of beer sold in six-packs of particular-sized cans), there is much less price dispersion among items at the lower level. One implication of this is that the problem in the Japanese CPI cannot be corrected by simply geometrically averaging the prices if the prices that the MIAC chooses all move in unison. However, this does not mean that the bias is absent. By contrast, the non-random sampling of goods means that the index does not correct at all for the the very real tendency of consumers to substitute away from high priced products and towards lower priced ones. Thus, while simply using geometric averages in the absence of random sampling may not correct the lower-level substitution bias, this does not mean that the index is unbiased. Rather the implication is that one needs both random sampling and geometric averaging to obtain the correct change in the cost of living. We therefore believe that the gap between the US CPI and the Japanese one is probably about about 0.4 percent.

\section{II. b. Upper Level Substitution Bias}

Upper-level substitution bias arises from the fact that in both the US (non-chained) CPI and the Japanese CPI, strata level indexes are aggregated using a Laspeyres formula. Thus, if the price of one stratum rises and another falls by the same amount, the index will record inflation because there is no adjustment for the fact that consumers may substitute consumption from the

\footnotetext{
${ }^{8}$ See Shiratsuka, Shigenori “Comments on 'Defining Price Stability in Japan: A View from America’ by C. Broda and D. E. Weinstein” May 30, 2007.
} 
expensive strata to the cheaper strata. Such estimates used to range between 0.1 and 0.2 percentage points per year.

Since the Boskin Commission's report has appeared, new data has become available that suggests that this bias is significantly larger. Estimates of the magnitude of the bias from ignoring substitutions across the CPI's roughly 8000 item-strata $^{9}$ are typically made by comparing the CPI with an alternative measure that does take substitution into account. ${ }^{10}$ Ever since the BLS began publishing a chained CPI using a Tornqvist formula at the upper level, it has become trivial to compute the bias arising from upper level substitution - the bias simply is the difference between the chained and unchained CPI's. Lebow and Rudd (2003) find the upper-level substitution bias to be around 0.5 percentage point for 1998-2000 in the U.S. Table 1 extends their comparison to the present to show that this bias has been roughly 0.4 percentage points for the period since 2000.

Shiratsuka (1999) computed the bias for Japan and came up with a much smaller number of 0.1 percent per year between 1970 and 1997. Since the MIAC produces both Paasche and Laspeyres indexes, it is possible to compare the Laspeyres index relative to the Fisher index. Since the Fisher index is a superlative index, the difference is a good approximation of the bias. In Table 2, we compute the upper level bias for Japan and find that while the bias was on average 0.1 percent per year until 2000, which is largely in line with Shiratsuka's estimate, between 2000 and 2005, it rose to 0.25 percent per year. We therefore use this more recent number for our estimate.

This number is very close to an estimate of the bias produced by Feldman (2006). Feldman compared a Laspeyres index of inflation with a geometric average of the price indexes

\footnotetext{
${ }^{9}$ Examples of item strata are uncooked ground beef in Dallas and hospital services in Atlanta.

${ }^{10}$ In January 1999, the BLS implemented measures to correct for the substitution that occurs within stratas. It is believed that most of this "within" bias has been corrected.
} 
that used historic weights. He estimates that between 2003 and 2005 a Laspeyres index would have overstated inflation by 0.3 percent per year relative to a geometric average of prices.

One element of the Japanese method of computing prices that is quite confusing is that while both Japan and the US now report a "chained” CPI, the methodology for chaining is completely different in the two countries. The US chained CPI (the C-CPI) uses a superlative index number formula at the upper level and geometric price averaging at the lower level. This means that the US chained CPI can be thought of as somewhere between a first and second order approximation of an arbitrary utility function.

MIAC “chaining” is actually what the BLS calls “annual weight updating”. The BLS now updates the base weights in the CPI every two years. While more frequent weight updating may reduce substitution biases, it is not sufficient to eliminate them. To understand why, think about how the problem arises. One of problems in Laspeyres indexes is that persistence in price movements can cause the base weights to deviate significantly from the current expenditure shares. Earlier versions of the CPI suffered from this problem as often the weights were updated often less than once a decade. If prices in some sectors are trending upward, then the Laspeyres index will overweight those sectors because it will not adjust for the fact that consumers will buy a relatively fewer items if the prices of those goods are rising relative to other goods.

Increasing the frequency of weight updating is conceptually quite different from adopting a superlative index. Regardless of the frequency of the weight updating, one cannot change the fact that the Laspeyres index uses historical weights, and consumption decisions today are going to be reflected in current weights. As long as relative prices have changed, the weights will differ. Thus, while the substitution bias may be mitigated by the fact that the MIAC now updates the CPI's base weights more frequently, they have not corrected for the fact that if prices change, the 
base weights will not be the same as the current weights. For goods whose prices are changing rapidly (e.g. high tech goods), the Japanese "chained” CPI will not correct for the substitution bias.

In fact, it is possible that the higher frequency of base updating has exacerbated the biases in the Japanese CPI. To understand why, consider the following example. Suppose that the prices of a given good have mean reverting fluctuations. If the price of the good is high in one period, consumers will substitute away from the good. In the next period, when the price falls, the fact that demand for the good was low in the previous period will mean that the price drop will be given a lower weight. This means that more frequent base updating can actually increase an inflationary bias. It is hard to know whether this happens in reality, but as the simple example makes clear, the Japanese form of "chaining” does not necessarily reduce the bias in the CPI.

Cage, Greenlees and Jackman (2003) show the precise impact of the biennially weightupdated CPI-U index series relative to a chained index or C-CPI-U index series over the 1990 to 2000 period in order to measure the anticipated difference between the two series. ${ }^{11}$ We present their results in Table 3. The average difference between a CPI-U whose weights are updated biennially and the C-CPI-U was 0.32 percent per year over this time period, which suggests that the Japanese method of chaining (i.e. base updating) does little to correct the underlying formula bias.

The gap between the weight-updated CPI-U and C-CPI-U appears to have widened in the later part of the decade. The average annual percent difference between the two indexes rose to 0.40 percent in 1996 to 2000, almost double that observed from 1991-1995. Analogously, the percent difference in simulated weight updated CPI-U and C-CPI-U 12-month indexes steadily increased over the decade. A likely contributor to the growing gap is increased dispersion in

\footnotetext{
${ }^{11}$ c.f. Table 5.2 of their paper.
} 
relative elementary index changes. In general, the CPI-U and the C-CPI-U will diverge to the extent that (a) component elementary indexes have rates of inflation that differ from each other, and (b) expenditure shares reflect a shift in consumer purchases toward those item categories that have fallen in relative price. Consequently, when there is more variation in price movement among elementary indexes, there is more room for the Laspeyres-based CPI-U and the superlative-based C-CPI-U to diverge. Price change in CPI elementary indexes varied more widely during the later part of the 1990s. The bottom line from this exercise is that the biennially updated CPI has a bias of the same magnitude that we observed for the general CPI-U, which leads us to conclude that increasing the frequency of weight updating is not effective in reducing the bias of a Laspeyres index

This is relevant for understanding why some of Shiratsuka's later work may not have identified this bias. Shiratsuka [2005 and 2006] estimates the differences between a fixed weight Laspeyres, a Japanese-style chained Laspeyres index, and the midpoint weighted Laspeyres (which uses weights between the base year and the current year) and finds that they all produce similar results. Unfortunately, none of the indexes that Shiratsuka examines are superlative indexes, and all of them use historic weights. If we know that the fixed weight Laspeyres has a significant substitution bias and that all of the MIAC's corrections to this index produce similar results, then the only logical conclusion is that these corrections failed to eliminate the bias. This is probably not that surprising since none of the indexes used by the Japanese government chain in the US sense. 


\section{II. c. Sampling}

One of the problems associated with the measurement of consumer prices in Japan and the US concerns the treatment of new retailers. Since the point of purchase is fixed in the sample, if new stores open that offer lower prices for the same goods, these price drops will not be captured by either the BLS or the MIAC. Neither country has procedures for adequately capturing changes in consumers’ purchasing habits. However, as Hausman and Leibtag (2004) point out that it is very hard to square the assumption that large discounters do not offer lower quality adjusted prices with the spectacular success that these stores have had in recent years in Japan and the US.

Wal-Mart and other large retailers have succeeded in building enormous businesses by offering the same goods for lower prices. Prior to 1990, large scale retailers found it difficult to open new stores in Japan due to restrictions imposed by the Large Scale Retail Law. Starting in 1990 and continuing through 2000 the Japanese government deregulated the opening stores in Japan (JETRO 2003). The net result of this was that mass merchandisers have made rapid progress in the Japanese market. For example Toys " $\mathrm{R}$ ” Us opened its first store in Japan in 1991 and had 133 stores by 2002. Costco opened its first store in 1999 and Wal-Mart acquired a 34\% stake in the Japanese retailer Seiyu in 2002 (JETRO 2003). Japanese retailing is clearly undergoing a fairly profound change being brought about by foreign and domestic massmerchandisers. Overall, the average sales floor space per retail establishment grew at annual rate of 4.0 percent between 1991 and 2004. By contrast, the rate of floor space per retail establishment growth was only 2.3 percent per year between 1979 and 1988 . This rate of growth 
has, if anything accelerated in recent years: floor space per retail establishment grew at a rate of 4.1 percent between 1999 and $2004 .^{12}$

. Shiratsuka (1999) argues that one can obtain estimates of the bias due to outlet substitution by looking at price movements following the Kobe earthquake. He obtains an estimate of the upward bias between 0.05 to 0.6. In the US, Hausman and Leibtag (2004) have examined the problem of outlet substitution more directly and find an outlet bias of around 0.3 to 0.4 per year for food products. This is somewhat larger than the original finding by Reinsdorf and motivates us to assume that the aggregate upward outlet bias in the Japanese CPI is probably also around 0.2 percent per year.

A second problem arises from how goods are chosen to be in the CPI in the two countries. MIAC uses a far simpler sampling procedure than the BLS in the construction of the lower level sample (c.f. MIAC [2006] and BLS [2006]). The Japanese approach to sampling of goods follows a top-down approach. Periodically, MIAC decides what items to sample and then adds them to the CPI. So, for example, one simply could not have done hedonic regressions on computers in Japan prior to 2000 because computers were not an element of the Japanese CPI. By contrast, the Japanese CPI was still tracking abacus lesson fees as late as 1999. Similarly CD players and mp3 players are not included but phonographs are (Shiratsuka [2006]). ${ }^{13}$ To the extent that the prices of computers, $\mathrm{CD}$ players, and mp3 players have fallen faster than the prices of abacus lessons and phonographs, one might suspect an upward bias in the CPI due to the slow rotation of items. Moreover, when new goods are added to the Japanese sample, there is no adjustment made for the fact that the prices of these goods may deviate from the prices of goods they replace. This is equivalent to assuming that none of the price movements associated

\footnotetext{
12 Japan Statistical Yearbook 2007.

13 The ipod was introduced into the Japanese CPI in 2007 [Sato (2007)]
} 
with the introduction of new goods is due to quality differences. This could be problematic if higher quality, higher priced goods replace older varieties.

Another important difference is that the BLS uses much broader definitions of its strata and then samples products based on the products available in stores. For example, the BLS has less specific strata and then uses interviews of store personnel to ascertain what the expenditure shares are for different products. Once they ascertain the sales weights of products, they randomly select products based using market shares as sampling weights.

The different procedures produce very different rates of product rotation. The BLS schedules a rotation of 25 percent of its sample every year based on these interviews and achieves full sample rotation every four years. While it is difficult to ascertain the rate of sample rotation in Japan, documents provided by MIAC indicate that Japan only rotated 10 percent of its sample in 2006.. ${ }^{14}$ Thus scheduled rotations in Japan seem to occur at one half to one third the rate of that of the US. Indeed the rate of product rotation is more comparable to the way the US CPI was constructed prior to 1981. Concerns over failure of the CPI to rotate its sample fast enough (particularly the location of purchases) resulted in a major revision of BLS procedures to correct these problems in 1998.

It is hard to know exactly how important the rotation of products is for the Japanese CPI. Most papers that have examined this (Lebow, Stockton, and Rudd [1994] and Shapiro and Wilcox [1997]) as well as the Boskin Commission report put the bias at 0.1 percent per year. This seems a conservative estimate for Japan given the even slower rates of rotation that exist

\footnotetext{
${ }^{14}$ The ten percent number was based on the 71 new items included in the 2000 revision of the CPI and 55 items eliminated out of a total of 598 items. Neither set of numbers includes forced rotations arising from the appearance and disappearance of goods. Shiratsuka [2006] reports that the MIAC reviews items and potentially changes them every 2.5 years.
} 
there. However, since we are uncertain of this effect, we will leave it out of our estimate of the overall difference between the US and Japanese CPIs.

\section{II. d. Quality/New Good Bias}

Since the CPI in both Japan and the US is defined using a common set of goods, there is no scope for adjusting prices based on the introduction of new goods. This is likely to bias the CPI upwards for a simple reason. One can think of creation of a new good as a price decline from the reservation price of that good to the price that is actually observed in the market (Hicks, 1960). Lebow and Rudd (2003) review the existing research on the quality bias and assess it to be 0.4 percent in the US in 2003. However, they admit that existing research provides them often with "little guidance" and that their estimates are largely judgmental. Indeed they only have a high degree of confidence in their estimates for 7 percent of the sample.

The US phased in a more extensive use of hedonics following the Boskin Commission report. Although hedonics is only used for a few strata where quality upgrading is likely to be important the impact has been quite large. The few sectors that are adjusted hedonically have a substantial impact on the overall index. The current usage of hedonics in the US is estimated by Lebow and Rudd (2003) to lower the measured rate of inflation by CPI by 0.2 percent.

It is hard to know what the comparable number for Japan would be. Recently, the importance of hedonic adjustments for computers has lessened. However, the fact that Japan uses hedonics so sparingly is a cause for concern. We believe that the greater usage of hedonics in the US probably means that the Japanese CPI deviates by around 0.2 from the US CPI.

Less is known about the level of bias for goods without a hedonic adjustment. The most comprehensive study of quality upgrading for a wide range of products is Broda and Weinstein 
(2007a). They examine all barcode data in the US and find that the rates of new product creation are enormous. Overall, 40 percent of all purchases of goods in their sample in a year did not exist four years earlier. This implies substantial impacts from product creation on the price index. Using CES and translog utility functions, Broda and Weinstein find that the upward bias from new goods is 0.8 percent per year between 1994 and 2003. To the extent that we think that Japanese consumers are at least as quality conscious as US consumers, one should expect comparable upward biases in Japanese data.

Extrapolating between the set of goods in the Broda and Weinstein sample and that of the whole CPI is difficult to do because we do not know rates of innovation in other sectors. However, there is good reason to believe that the Broda and Weinstein estimate is plausible for the entire CPI. First, the sample of goods they examine is quite broad, comprising 40 percent of all goods categories in the CPI. Second, the set of goods they examine, food and beverages, groceries, and mass merchandising goods are goods in which new product innovation is likely to be relatively small. These are not the sectors that one typically thinks of as the most innovative ones in the economy. Indeed the Boskin Commission had assumed that the bias in food and beverages was only 0.1 percent per year - a fraction of the actual bias. As a result, there is good reason to believe that these estimates, if anything, understate the aggregate bias.

\section{Summing up the Biases}

Table 4 summarizes the biases in the U.S. prior to the modifications that occurred after the Boskin commission and reports the estimated differences with the Japanese current methodology of computing the CPI. In a very careful and controversial paper, Shiratsuka [1999] estimated that there was an upward bias of 0.9 percent per year in the Japanese CPI. 
To the extent that we can apply US estimates of these biases to Japanese data, it appears that there are subastantial biases still to be corrected. Table 4 summarizes the biases that we have been discussing. Upper and lower level substitution biases are likely to amount to around 0.2 and 0.4 percent per year respectively. Outlet rotation biases are likely to stand at 0.2 percent. New goods and quality upgrading is likely to add another 0.8 percent per year to this in both Japan and the US. Hedonic adjustments are likely to reduce the US CPI relative to the Japanese CPI by 0.2 percent per year. This suggests a total bias of 1.8 percent in Japan and 1.0 percent per year in the US. This suggests that the level of bias in Japan is is approximately the same as the upward bias in the US CPI prior to the Boskin Commission revisions.

These estimates based on US data are not out of line with estimates of the bias based on Japanese data. Ariga [2003] examined the difference between point of sale price data and the prices reported in the CPI. He consistently found that the CPI overstated inflation by 1.5 percent to 2 percent per year in the sample of goods he examined. Thus, there seems to be substantial amounts of evidence in both the US and Japan that the methodology used by the MIAC to measure biases substantially overstates inflation.

In Figure 1, we conduct a counterfactual exercise of assessing what the Japanese price level would be if MIAC had changed the methodology for computing the Japanese CPI along the same timetable as the BLS. Here we assume that lower level substitution bias was eliminated in the US in 1999, the upper level bias was eliminated in 2002, and the quality bias was reduced by 0.15 percent in 2000 and 2001 and 0.2 thereafter. As one can see from the figure, between 1999 and 2006, the official index fell by 3.2 percent. However, if the BLS had received the same data over the same time period they would have produced an 8.4 percent drop in the price level. In other words, while the Japanese CPI was registering an average rate of deflation of 0.5 percent 
per year, had the MIAC been keeping up with advances in CPI being implemented by the BLS, they would have been recording deflation of 1.2 percent per year. This suggests that methodological differences are potentially important in understanding the low rate of deflation in Japan. These numbers are all the more striking if one realizes that if one adjusted for quality in the manner suggested by Broda and Weinstein (2007) and the outlet bias as suggested by Hausman and Leibtag (2004) the Japanese rate of deflation would have been greater by another 1.0 percent or 2.2 percent per year!

\section{The impact of CPI biases on policy}

IV. a. Comparing real per capita GDP across countries

Table 5 presents evidence on the implications of the bias in the CPI for understanding Japan’s economic performance since 1998. We computed real per capita private consumption growth using Japanese and US national accounts and CPI data in the first and third columns of the table. For Japan we used the usual CPI and for the US, we used the chained CPI. As one can see from the final row, if one simply looked at the official data, US real per capita consumption growth averaged 2.6 percent per year over this time period while in Japan it was an anemic 0.4 percent. However, if one adjusts for the biases in the Japanese data suggested by Table 4, then the Japanese growth rate rises to 1.2 percent per year. Still well below that of the US, but considerably higher than what the official numbers suggest.

\section{IV. b. Fiscal Policy}

There are many policy implications that arise from better measurement of prices. One of the most important concerns the role of the CPI on the fiscal situation. Eliminating biases in the 
Japanese CPI is likely to have a major positive impact on Japan’s fiscal situation. Although Japanese tax brackets are not indexed to inflation, many Japanese government transfers, such as public pensions, are indexed to the CPI. If the CPI is biased, then this means that the government is spending vastly more than it should. Correcting the biases in the CPI would mean that inflation adjustments to government benefits and taxes would more accurately reflect changes in the cost of living. It would also reduce future federal deficits and the national debt. As the US Congressional Budget Office stated in 1994: "If the change in the CPI overstates the change in the cost of living, this means that some federal programs would overcompensate for the effect of price changes in living standards, and wealth would be transferred from younger and future generations to current recipients of federal programs—an effect that legislators may not have intended.”

The same logic applies to Japan. A correction of the CPI bias would work to reduce outlays that are automatically linked to the CPI. Currently not only social security spending is linked to the CPI. Japanese non-medical pension and welfare benefits totaled 58 trillion yen in 2004 or 12 percent of GDP. If the Japanese CPI is rising by more than the true cost of living, these benefits are likely to be rising too rapidly. Unlike the US, the elimination of the CPI bias would not raise government revenues since tax brackets are not indexed to inflation.

Figure 2 shows the overall reductions in deficits in the next 10 years that would result from correcting an overstatement of 1.8 percentage points in the CPI if conventionally measured inflation stood at 2.7 percent per year or more. ${ }^{15}$ Here, we use Peter Morgan’s (2004) forecasts of pension expenditures following the 2004 pension reforms and assume that non-health related welfare expenses continue to be 29 percent as large as pension expenses. If we assume that the real

\footnotetext{
${ }^{15}$ Given the fact that the growth of nominal expenditures on pensions are legally bound below by zero or CPI inflation less approximately 0.9 percent, the amount of savings is dependent on the rate of inflation. This implies that full savings from reindexing would not be achievable without an inflation rate of 2.7 percent per year. We are indebted to R. Anton Braun for pointing this out.
} 
cost of government debt is 2 percent per year, then this implies that in 2017 alone correcting the biases in the CPI would reduce the Japanese government deficit by $¥ 14$ trillion -3 percent of GDP! The accumulated reductions in deficits after 10 years amounts to more than $¥ 69$ trillion or almost 14 percent of GDP. To put this number into perspective, it is more that total central government tax receipts in fiscal year 2006. Clearly, correctly measuring inflation can have important fiscal consequences for the government.

\section{IV. c. Monetary Policy}

A second important policy implication concerns monetary policy. If the Japanese CPI is biased upwards by 1.8 percent, then this suggests that unless current measured inflation is at least 1.8 percent per year, the central bank would not be achieving a target of price stability. However, there is good reason to believe that inflation would need to be substantially higher in order to instill confidence that the economy was still not suffering from deflation.

Given the high degree of underlying price volatility of individual price quotations, one can do a back-of-the-envelope calculation about the standard error of the Japanese CPI due to the fact that inflation is measured from a sample of goods. If we assume that the typical monthly movement in an underlying price is around 20 percent, then this implies that with 95,000 price quotes in the Japanese data, the standard error of a monthly CPI release should be equal to 20 percent divided by the square root of 95,000 or about 0.06 percent at a monthly frequency or about 0.7 percent at an annual frequency. Ignoring the bias, this means that the inherent measurement error associated with the CPI implies that one cannot reject that a monthly CPI number isn’t zero at the 95 percent unless inflation is over 1.4 percent per year.

How good is this back-of-the-envelope calculation? Broda and Weinstein (2007a) bootstrap the measurement error of the US CPI by drawing on their sample of 700,000 barcodes 
to see how much sample selection matters. In their estimation, the standard error of the CPI at a quarterly frequency is approximately 0.6 percent at the quarterly frequency, which is very close to the intuition one gets from the simple exercise that we just considered. Moreover, for inflation innovations, they find that the standard deviation of the measurement error is close to 0.9 percent. This suggests that there measurement error is likely to be sufficiently large that it is unlikely that there is much information contained in high frequency movements in the Japanese CPI.

The standard deviation falls to 0.1 percent at a four-quarter frequency in US data, which suggests that much of the measurement error reflects sales and other high frequency price fluctuations. However, even so, if the numbers for Japan are comparable to the US numbers, then this suggests that the 95-percent confidence bands on even annual fluctuations of in the CPI are probably close to plus or minus 0.2 percent per year. This suggests that a central bank wishing to be confident that the economy was not in deflation should not let inflation fall below 2.0 percent. Interestingly, this number is larger than the definition of price stability used by any members of the BOJ's policy board.

\section{Conclusion}

Japan has not invested as heavily as the US in the production of statistics. In this paper, We have discussed a few of the many ways in which an upward bias can creep into the CPI. These biases seem to lead to an upward bias in the official number of around 1 percent relative to the US methodology. Moreover the standard error of mismeasurement implies that a central bank interested in preventing deflation should target inflation of closer to 2.0 percent.

The decision not to invest in better statistics is largely motivated by inertia and an attempt to hold down the cost of government. In this paper, we suggest that this strategy may be 
"pennywise but pound foolish.” There is good reason to believe that the resulting upward bias in the CPI has had and will continue to have a large negative impact on the Japanese government deficit. Over the next ten years, the inflationary bias in the Japanese CPI is likely to cost Japan 73 trillion yen. This amount is far more than the cost of revising the index. Moreover, Japanese policymaking is hampered by inadequate statistical resources. Even in 2006, measurement errors have resulted in the central bank thinking that there was inflation when in fact there was deflation. This can have potentially serious consequences for monetary policy. 
Table 1: The Impact of US Chaining in US CPI measures

\begin{tabular}{cccc}
\hline \hline & CPI & C-CPI & Average Inflation Difference \\
\cline { 2 - 4 } 1999 & 100.0 & 100 & \\
2000 & 103.4 & 102 & $1.4 \%$ \\
2001 & 106.3 & 104.3 & $0.6 \%$ \\
2002 & 108.0 & 105.6 & $0.3 \%$ \\
2003 & 110.4 & 107.8 & $0.2 \%$ \\
2004 & 113.4 & 110.5 & $0.2 \%$ \\
2005 & 117.2 & 113.7 & $0.5 \%$ \\
2006 & 121.0 & 116.9 & $0.4 \%$ \\
Average & & & $0.5 \%$ \\
\hline
\end{tabular}

Source: U.S. Bureau of Labor Statistics.

Table 2: Upper Level Substitution Bias in Japan

\begin{tabular}{|c|c|c|c|c|}
\hline & Laspeyres & Paasche & Fisher & $\begin{array}{c}\text { Annual Bias in } \\
\text { Percent }\end{array}$ \\
\hline 1970 & 130.4 & 126.0 & 128.2 & 0.36 \\
\hline 1975 & 172.4 & 171.0 & 171.7 & 0.09 \\
\hline 1980 & 137.2 & 134.6 & 135.9 & 0.20 \\
\hline 1985 & 114.4 & 113.3 & 113.8 & 0.10 \\
\hline 1990 & 106.2 & 105.5 & 105.8 & 0.07 \\
\hline 1995 & 106.4 & 106.2 & 106.3 & 0.02 \\
\hline 2000 & 101.0 & 99.9 & 100.4 & 0.11 \\
\hline 2005 & 97.3 & 94.9 & 96.1 & 0.25 \\
\hline
\end{tabular}

Source: MIAC Shohisha Bukka Shisu no Kaisetsu 2005, p. 10 and authors' calculations Laspeyres, Paasche, and Fisher indexes are computed using a base year that is five years before each entry 
Table 3: The US and Japanese way of Chaining

\begin{tabular}{|c|c|c|c|}
\hline Year & $\begin{array}{l}\text { Inflation from } \\
\text { Simulated } \\
\text { Biennially } \\
\text { Updated CPI-U }\end{array}$ & $\begin{array}{c}\text { Inflation from } \\
\text { Simulated Final } \\
\text { C-CPI-U }\end{array}$ & $\begin{array}{c}\text { Percent } \\
\text { Difference }\end{array}$ \\
\hline 1991 & 4.0 & 3.9 & 0.1 \\
\hline 1992 & 3.2 & 2.7 & 0.5 \\
\hline 1993 & 3.0 & 2.8 & 0.2 \\
\hline 1994 & 2.7 & 2.4 & 0.2 \\
\hline 1995 & 2.6 & 2.4 & 0.2 \\
\hline 1996 & 3.0 & 2.7 & 0.3 \\
\hline 1997 & 2.2 & 1.8 & 0.4 \\
\hline 1998 & 1.4 & 0.9 & 0.5 \\
\hline 1999 & 2.2 & 1.7 & 0.5 \\
\hline 2000 & 3.3 & 2.8 & 0.5 \\
\hline \multirow{2}{*}{\multicolumn{3}{|c|}{$\begin{array}{l}\text { Average annual percent difference: } \\
\text { Average annual percent difference, 1991- } \\
\text { 95: } \\
\text { Average annual percent difference, 1996- } \\
\end{array}$}} & 0.3 \\
\hline & & & 0.2 \\
\hline
\end{tabular}

Source: "Introducing the Chained Weighted CPI"

Robert Cage, John Greenlees, and Patrick Jackman

U.S. Bureau of Labor Statistics

Table 4: Estimates of CPI Bias

\begin{tabular}{|c|c|c|c|c|}
\hline $\begin{array}{l}\text { Country } \\
\text { Category of Bias }\end{array}$ & $\begin{array}{c}\text { US } \\
\text { Pre-1999 Bias } \\
\end{array}$ & $\begin{array}{c}\text { US } \\
\text { Post } 1999 \text { Bias } \\
\end{array}$ & $\begin{array}{c}\text { Japan } \\
\text { Bias } 2006\end{array}$ & $\begin{array}{c}\text { Japan - US } \\
\text { Post } 1999 \text { Difference }\end{array}$ \\
\hline Upper-level substitution & 0.4 & 0 & 0.2 & 0.2 \\
\hline Lower-level substitution & 0.4 & 0 & 0.4 & 0.4 \\
\hline New outlets & 0.2 & 0.2 & 0.2 & 0.0 \\
\hline Quality bias excluding Selected Goods & 0.8 & 0.8 & 0.8 & 0 \\
\hline Hedonics on Selected Goods & 0.2 & 0 & 0.2 & 0.2 \\
\hline TOTAL BIAS & 2.0 & 1.0 & 1.8 & 0.8 \\
\hline
\end{tabular}

* Selected Goods includes Computers, Cellphones, 
Table 5: Cross-Country Growth Comparisons

\begin{tabular}{cccc}
\hline \hline & $\begin{array}{c}\text { Real Household Consumption Per Capita growth } \\
\text { (annual \%) } \\
\text { Japan } \\
\end{array}$ & $\begin{array}{c}\text { Japan } \\
\text { Official Statistics }\end{array}$ & $\begin{array}{c}\text { US } \\
\text { using US } \\
\text { methodology }\end{array}$ \\
\cline { 2 - 4 } 1999 & 0.5 & 1.3 & 3.5 \\
2000 & 0.3 & 1.1 & 2.7 \\
2001 & 1.1 & 1.9 & 0.8 \\
2002 & 0.3 & 1.1 & 1.6 \\
2003 & -0.5 & 0.3 & 1.5 \\
2004 & 0.7 & 1.5 & 2.8 \\
2005 & 0.8 & 1.6 & 2.0 \\
2006 & 0.1 & 0.9 & 1.7 \\
Cumulative & 3.1 & 8.7 & 14.9 \\
Average & 0.4 & 1.2 & 2.1 \\
\hline
\end{tabular}

Real Per Capita Household Consumption growth in Japan was computed using the Economic and Social Research Institute's data on nominal household consumption deflated by the Japanese CPI and population data taken from the IMF's International Financial Statistics. For the US numbers, we used nominal personal consumption data from the Bureau of Economic Analysis and deflated it by the C-CPI-U for 1999-2006. We used Lebow and Rudd's (2003) estimate of the difference between the C-CPI-U and the CPI-U in conjunction with the CPI-U numbers to compute the movement in the price index between 1998 and 1999.

Source: IFS, BLS and MIAC. 
Figure 1

Japanese Prices Computed with US and Japanese CPI Methodologies (1998 - 2005)

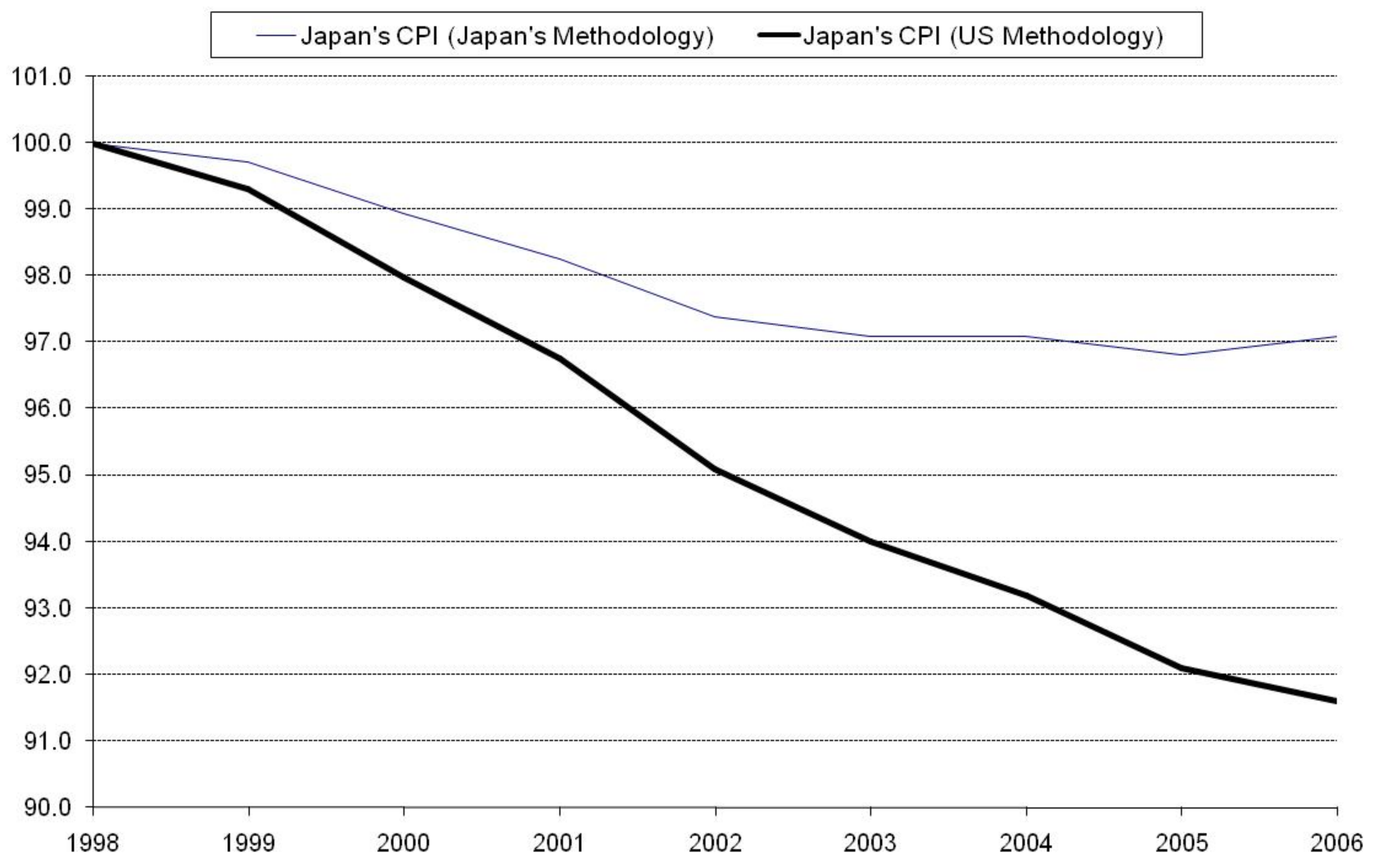


Figure 2

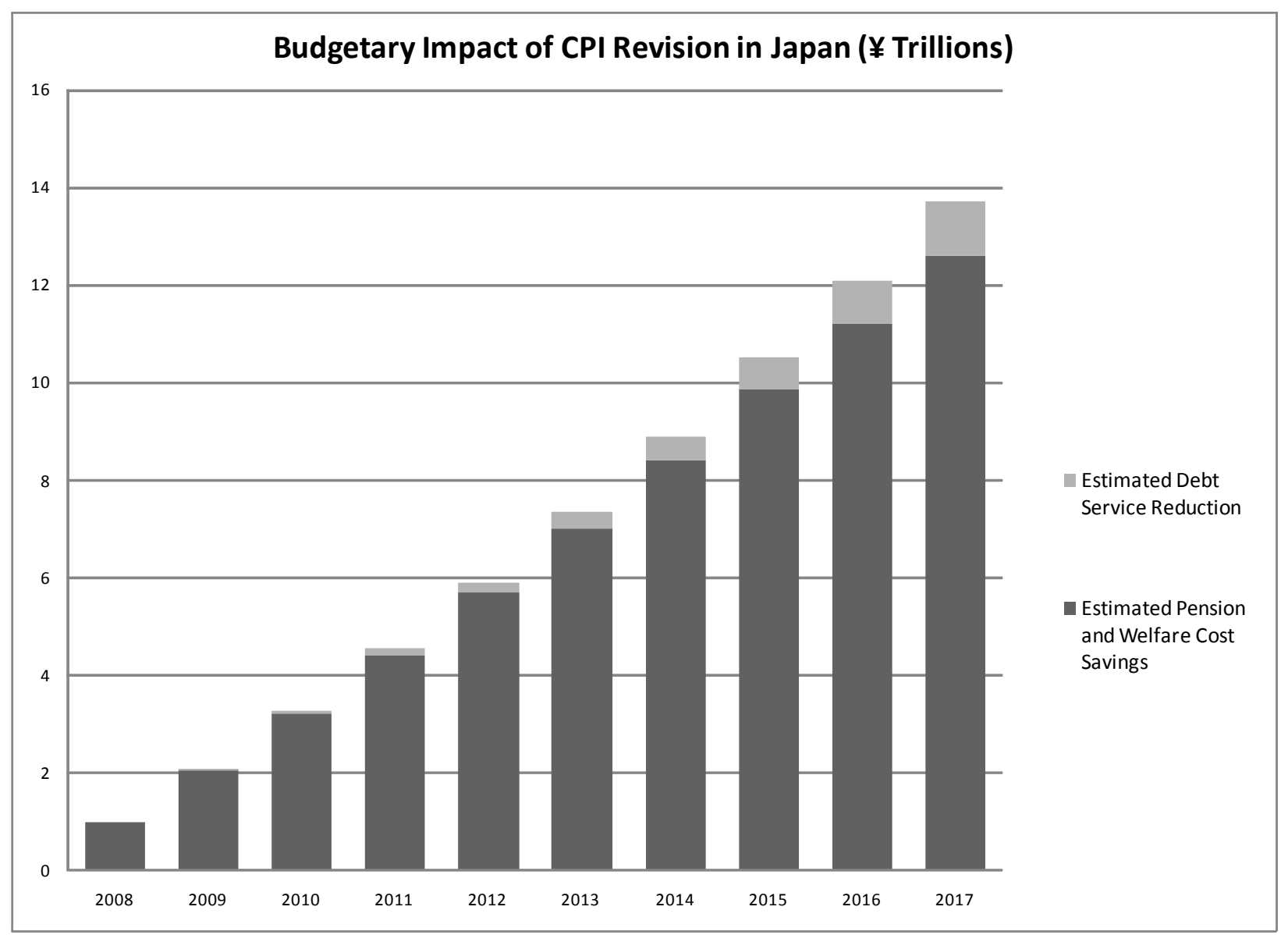




\section{References (Incomplete)}

Boskin, Michael J. and Dale W. Jorgenson (1997) The American Economic Review, Vol. 87, No. 2, Papers and Proceedings of the Hundred andFourth Annual Meeting of the American Economic Association. (May), pp. 89-93.

Broda, Christian and David E. Weinstein (2007a) "Product Creation and Destruction: Evidence and Price Implications,” NBER Working Paper 13041, April.

Broda, Christian and David E. Weinstein (2007b) "Price Indexes and Deviations from the Law of One Price,” University of Chicago Graduate School of Business, mimeo.

Congressional Budget Office (1994) "Is the Growth in the CPI a Biased Measure of Changes in the Cost of Living?" CBO papers, Congress of the United States, Washington, DC, October.

Diewert, W. Erwin (1976) “Exact and Superlative Index Numbers,” Journal of Econometrics. 4 pp 114-145.

Diewert, W. Erwin (1993) “The Early History of Price Index Research,” in W.E. Diewert and A.O. Nakamura (Editors) Essays in Index Number Theory. Volume 1 Elsevier Science Publishers B.V.

Japan External Trade Organization (JETRO) (2003) “A New Era in Japan’s Retailing Market: Deregulation Paves the Way for Inroads by Foreign Groups,” Invest Japan, Special Edition Vol. 2, pp. 14-14.

Hausman, Jerry and Ephriam Leibtag (2004) "CPI Bias from Supercenters: Does the BLS Know that Wal-Mart Exists?” NBER Working Paper 10712.

Lebow, David E., John M. Roberts, and David J. Stockton, "Monetary Policy and 'The Price Level'," mimeo, Board of Governors of the Federal Reserve System, 1994.

Morgan, Peter (2004). “Japan’s Pension Reforms: The Myth of the Pension 'Crisis’”, HSBC mimeo February.

Klenow, Peter J. and Oleksiy Kryvtsov, 2005. "State-Dependent or Time-Dependent Pricing: Does It Matter for Recent U.S. Inflation?” Stanford University mimeo.

National Institute for Population and Social Security Research (2007) "The Cost of Social Security in Japan,” IPSS Statistical Report No. 17.

Reinsdorf, M., 1993. “The Effect of Outlet Price Differentials in the U.S. Consumer Price Index.” In Price Measurement and Their Uses, M.F. Foss, M.E. Manser and A.H. Young (eds.), NBER Studies in Income and Wealth, Vol. 57, 227-254. 
Sato, Masaaki (2007) “Comments on Dr. Weinstein’s Paper,” Ministry of Internal Affairs and Communications mimeo.

Shiratsuka, Shigenori (1999) "Measurement Errors in the Japanese Consumer Price Index," Monetary and Economic Studies, Bank of Japan, December, pp. 69-102.

Shiratsuka, Shigenori (2005) "Wagakuni no Shohisha Bukka Shisu no Keisoku Gosa Iwayuru Joho Baiasu no Genjo,” [Measurement Error of Japan’s Consumer Price Index: What do We Know of the Upper-Level Bias], Bank of Japan Review, Bank of Japan November, pp. $1-7$.

Shiratsuka, Shigenori (2006) “Measurement Errors in the Japanese CPI,” Bank of Japan, mimeo. 